\title{
NARRATIVAS EM DIÁLOGO: IMBRICAÇÕES \\ GEOGRÁFICAS, LITERÁRIAS E EDUCACIONAIS ENTRE A GEOGRAFIA DE DONA BENTA (1935) E LE TOUR DE LA FRANCE PAR DEUX ENFANTS (1877)*
}

\author{
- FILIPE RAFAEL GRACIOLI ** \\ - JOÃO PEDRO PEZZATO ***
}

\begin{abstract}
Resumo: 7 texto que se apresenta estabelece aproximações entre a literatura infantil e a gengrafia a partir da análise de narrativas de caráter gengráfico orientadas à criança leitara do períado entre o final do sécula XIX e início do sécula XX: a Geografia de Dana Benta (1935) de Manteira Lobato e o Le tour de la France par deux enfants, de G. Bruñ (1877). $\mathrm{Q}$ objetivo do estuda reside na discussão das aproximações e distanciamentos entre as narrativas em alguns aspectos, como o da criação de identidades nacionais, an que se justapõem outros temas afins. Como referencial metadalógico apresenta-se o paradigma indiciário, que aponta para a ideia de que há indícios no texto que revelam particularidades negligenciáveis, como saberes relevantes na compreensão da visão de munda dos autores. A hipótese perseguida reside na ideia de que Lobata tenha se inspirada no livro francês para a desenvolvimenta da sua narrativa, dadas as semelhanças de enredo entre os textos, além das similitudes entre os conteúdos de referência aos campos da educaçãa e da geggrafia. ( estuda recupera um tipo de escrita que inaugura para a infância uma literatura de itinerário, uninda literatura e geografia de moda jamais visto na escrita orientada à criança no ocidente.

Palavras-Chave: literatura infantil; geggrafia; educação.
\end{abstract}

\section{Introdução}

Os saberes geográficos, tão antigos quanto a própria literatura, sempre estiveram alocados nas diversas linguagens utilizadas pelo gênero humano para fins de comunicação e de socialização. Para a linguagem desenvolvida no ocidente, recupera Geraldi (2000) que o seu percurso "se deu a partir de sua característica sonora criadora do alfabeto e aprimorada com a capacidade de segmentação pelo homem do 
continuum da fala em elementos cada vez menores: as palavras, as sílabas, os fonemas.” (GERALDI, 2000, p. 105).

Assim posto, a linguagem e a literatura surgem no contexto do discurso proferido pelas camadas que se apropriaram do artefato coletivamente construído - a escrita, de modo que qualquer outra escrita que não se conforme ao discurso proferido pelas camadas que se apropriaram deste artefato são consideradas não escritas; daí o grande poder que reside na língua e na linguagem, um poder de determinação de discursos e de seus sujeitos sociais. Barthes (2010) chama a atenção para o poder que a linguagem traz consigo através do tempo, sendo a linguagem correspondente a uma legislação, um rol aglutinador de regras para o bom uso da língua, que se inscreve como o seu código, de acordo com a necessidade da expressão humana. Deste formato emoldurador da expressão humana que identifica a linguagem "não vemos o poder que reside na língua, porque esquecemos que toda língua é uma classificação, e que toda classificação é opressiva [...]” (BARTHES, 2010, p. 12).

No entanto, na escrita que se observa em Monteiro Lobato, autor eleito para nosso estudo, a literatura que liberta não se engessa por ela mesma: para as crianças era preciso contar, sair-se aos limites da literatura que submete língua e linguagem, mas que delas depende para se firmar, usar do artifício da oralidade e dar vida àquilo que ele denominara de desliteraturização, a escapada da formapadrão de pensar a infância, o conhecimento, os lugares, o espaço, um movimento novo na história brasileira, de importância não só literária, mas cultural, de modo mais abrangente.

Na língua está a grande magia e a grande importância do discurso reacionário de Monteiro Lobato. Este aspecto do poder de determinação que representa a língua é o mesmo responsável pela criação daquilo que mais importa na relação humana com o espaço geográfico, a criação de uma geograficidade que, segundo Dardel (2011) vem a significar “[... a experiência geográfica, tão profunda e tão simples [que] convida o homem a dar à realidade geográfica um tipo de animação e de fisionomia em que ele revê sua experiência humana, interior ou social." (DARDEL, 2011, p. 6 - adaptado).

Esta geograficidade permitida pela relação do homem com o espaço geográfico e que passa pela língua como criadora de identidade, de pertencimento ao lugar vem requerer o sentido da consciência - e a sensibilidade - do espaço, do ser que existe no espaço, assim como a historicidade, que é a consciência do homem no tempo. A 
importância desta experiência geográfica está na constatação de que em ambas as narrativas eleitas para estudo há o desenvolvimento e o reconhecimento de geograficidades pelo destaque da força da nação, geograficidades estas pautadas no senso de pertencimento a um território geopolítico e, sobretudo, marcadamente cultural.

Neste sentido, o estudo que apresentamos estabelece relações entre dois livros de literatura infantil a partir dos aspectos de suas posturas geográficas, literárias e de veiculação de linguagens e de geograficidades subversoras de padrões culturais aos seus tempos, a saber: a Geografia de Dona Benta (1935) de Monteiro Lobato, e o Le tour de la France par deux enfants - devoir et patrie, publicado em 1877 por G. Bruno, que se inserem na história da educação no Brasil e no mundo ocidental como narrativas pioneiras orientadas para um nicho social em expansão quanto ao seu reconhecimento como indivíduo social, bem como pináculos da literatura infantil de seus tempos.

A importância da seleção do texto de Monteiro Lobato se justifica pela relevância literária e didática que apresentou no momento de seu surgimento e também pelas décadas que se seguiram após a sua edição, de modo que pelo viés literário infantil, sobretudo, se coloca como o fundador de uma geograficidade para o espaço brasileiro, acrescenta a crítica política e cultural como elementos de reforço do pensamento libertador das filosofias dominantes de seu tempo, atribui à literatura uma possibilidade de se fazer Geografia e de ensinar um conteúdo espacial que foge ao meramente técnico e racional sem, no entanto, abandonar $\mathrm{o}$ rigor necessário ao aprimoramento da formação geográfica necessária ao jovem leitor e estudante. Entre outras importâncias, a Geografia de Dona Benta torna a criança a responsável pelo universo que ela própria cria e se permite viver, tomando a experiência do vivido como a chave para o entendimento de sua própria formação como ser humano e ser geográfico.

Quanto ao texto publicado por G. Bruno sua justificativa reside nas proporções tomadas pela sua difusão em meios escolares e de alfabetização em grande parte do mundo ocidental, sendo um livro amplamente utilizado como fonte de inspiração para a formação de pensamentos geográficos e de condutas culturais, especialmente no Brasil, onde grandes nomes da literatura nacional foram por ele inspirados. A narrativa expressada no texto de G. Bruno posiciona-se na história do campo da educação como pináculo para o 
desenvolvimento de uma literatura orientada à infância que se pode dizer itinerária, jamais verificada na literatura infantil ocidental.

Distante do propósito de realizar um estudo ao molde de uma literatura comparada, o texto que se apresenta estabelece aproximações e distanciamentos entre as duas narrativas eleitas para estudo, no sentido de busca pelas imbricações que nos permitem perseguir a hipótese de que o autor brasileiro tenha se inspirado na narrativa francesa para a elaboração de seu texto, inaugurando com sua técnica de escrita pautada na fantasia uma literatura que se pode dizer de itinerário jamais vista no Brasil e no mundo ocidental.

\section{Os passos da investigação}

A proximidade de conteúdo entre as tramas, qual seja, a viagem realizada pelas personagens da Geografia de Dona Benta e a viagem realizada pelas personagens principais do Le tour de la France par deux enfants, a saber, a busca pela exploração do território brasileiro e francês, respectivamente, além do objetivo de ressaltar a pátria como valor universal no contexto insurgente do Estado-nação, essa proximidade oferece um indício para a hipótese que perseguimos, a de que Monteiro Lobato tenha entrado em contato com a narrativa de G. Bruno, por se tratar de uma literatura clássica para as crianças das elites cultural e econômica de seu tempo e por ser escrita no idioma universal à época, o francês, do qual Lobato desfrutava como leitor.

A importância do estudo reside na maneira como Lobato desenvolve a sua narrativa e apresenta a ideia de pátria à infância: se no Le tour de la France par deux enfants $\mathrm{G}$. Bruno se utiliza da viagem real por dois meninos pelo território francês, de maneira a se permitir conhecê-lo para defendê-lo como cidadãos pertencentes à nação, na Geografia de Dona Benta a viagem se faz pela imaginação da criança leitora, por meio do recurso da imaginação levantado inclusive pelas personagens da narrativa.

Para a elaboração das análises e comparações entre as narrativas foi eleito o paradigma indiciário como caminho metodológico, o buscar pelos indícios que as aproximam, bem como pelos saberes negligenciáveis, que passam despercebidos na leitura de um tex to e que desempenham importância ímpar na identificação de uma visão de mundo. Em Sinais: raízes de um paradigma indiciário (1999) Carlo Ginzburg apresenta uma proposta metódica em que indica: “[...] é preciso não se basear, como normalmente se faz, em características mais vistosas, portanto mais 
facilmente imitáveis [de uma obra artística]. Pelo contrário, é necessário examinar os pormenores mais negligenciáveis, e menos influenciados […”. (GINZBURG, 1999, p. 144 adaptado).

O paradigma indiciário justifica-se pela noção de que há sinais que permitem compreender os pontos pouco luminosos da realidade, competindo à intuição captálos. Ginzburg assinala que os saberes captáveis a partir da atenção aos indícios se apresentam como formas de saber tendencialmente mudas, de modo que não constituem saberes modulados por regras formais. "Nesse tipo de conhecimento entram em jogo elementos imponderáveis: faro, golpe de vista, intuição." (GINZBURG, 1999, p. 179).

Para tanto, neste estudo, buscamos uma consonância entre o apresentado por Carlo Ginzburg e o propósito discutido por Mikhail Bakhtin, da qual compreendemos que não se pode considerar que o pensamento de Monteiro Lobato ou de G. Bruno esteja de todo apresentado nos livros em estudo, nem mesmo que qualquer parte garfada numa leitura textual seja representativa da visão de mundo de seu criador. Nas palavras de Bakhtin: “o autor de uma obra só está presente no todo da obra, não se encontra em nenhum elemento destacado desse todo, e menos ainda no conteúdo separado do todo. [ ...] Vemos o criador apenas em sua criação, nunca fora dela." (BAKHTIN, 2003, p. 399-400).

Neste sentido, partimos para uma análise inicial de cada narrativa em que a ideia está em apresentar os aspectos introdutórios de cada texto com o intuito de se fazer conhecê-las para assim proceder à análise de comparação entre ambas, ressaltando os limites ou indícios que as aproximam e distanciam, analisados em sua trama e em suas visões de geografia e de geograficidades na composição textual.

\section{Uma análise das narrativas infanto- juvenis}

Publicada em 1935, a Geografia de Dona Benta conta a viagem imaginária das personagens da obra Sítio do Pica-pau Amarelo pelos continentes do planeta Terra a bordo de um navio também imaginário, o Terror dos Mares. Nesta viagem, que resgata a oralidade, o modo de Lobato fazer Geografia destoa da tradição enciclopedista e decorativa atribuída ao conhecimento geográfico de seu tempo. No movimento de idas e vindas pela memória o autor resgata o conceito de artesanalidade do conhecimento e a maneira como ele se dispõe na sociedade, chamando a responsabilidade do processo educativo para a própria criança leitora, 
para seus familiares, seus amigos e para a própria sociedade, em um momento da história em que a abertura democrática da escola abdicava para si a responsabilidade da formação humana que antes cabia à oralidade. Conforme aponta Gracioli (2013):

$$
\begin{aligned}
& \text { Lobato apresenta-se aos seus leitores } \\
& \text { como um narrador e, no caso da obra } \\
& \text { estudada, narrador de um espaço em } \\
& \text { formação [...]; é aí que a sua Geografia } \\
& \text { se faz importante como obra } \\
& \text { pedagógica, ao permitir que a narrativa } \\
& \text { persista entre aqueles que mais } \\
& \text { experienciam: as crianças. }
\end{aligned}
$$
(GRACIOLI, 2013, p. 7).

Em termos objetivos, a Geografia de Dona Benta trata-se de uma narrativa orientada à infância do início do século XX dirigida pelo ideal nacionalista $\mathrm{e}$ desenvolvimentista do período, fortemente identificável no texto e no pensamento lobatiano. Alguns sinais da ideologia e do pensamento do autor são bastante notáveis, sobretudo quando se trata de explorar as terras brasileiras. Como exemplos da ideologia nacionalista e orientada para o progresso econômico expressada na narrativa, é significativo, entre outros, o trecho que versa sobre o Rio Grande do Sul, em que Lobato evidencia uma dobra do tempo sobre o espaço, anulando o segundo em detrimento do primeiro:

- Ah, o Rio Grande do Sul é uma das partes mais interessantes, mais ricas e de mais futuro do Brasil. Tem todas as condições de clima e topografia para desenvolver-se cada vez mais. O povo é sadio e corajoso. E entusiasta. Um povo feliz. As culturas são variadíssimas; produz até trigo; e as indústrias se desenvolvem com muita força. Em matéria de vinho o Rio Grande está na ponta. (LOBATO, 1988, p. 25).

Nos locais visitados pelas personagens e pelo leitor da sua Geografia, Lobato recupera uma importante faceta da formação da identidade brasileira; nestes espaços visitados a paisagem, como categoria espacial, se coloca como a máscara que ao mesmo tempo identifica a nação pela exuberância do meio (figura 1) e ao mesmo tempo oculta a situação precária da política brasileira, carente de figuras de potencial memorável para o país, denúncia que há muito vinha se delineando entre a classe intelectual do país, e que em Lobato se deu por meio da literatura infantil, inclusive. 


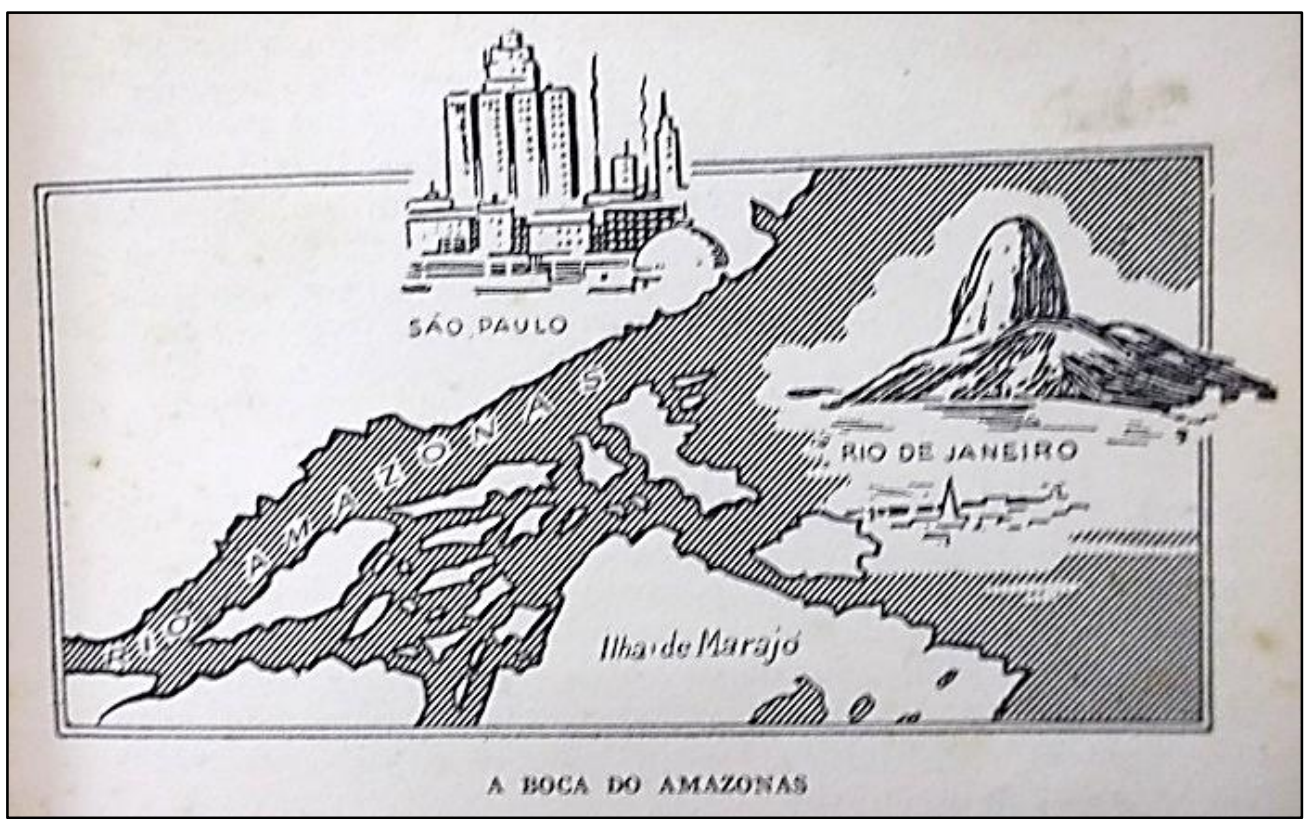

Figura 11 - Ilustrações como esta, que reforçam estereótipos de lugares como identidades associáveis ao espaço do nacional são frequentes ao longo da narrativa de Lobato. Além disso, nota-se que não há preocupação em formar leitores gráficos do espaço: a dificuldade de localização pela escala também configura o aspecto geo(gráfico) do texto. (LOBATO, 1935, p. 81)

Por meio das constatações das personagens que representam a infância leitora e sujeitos de uma experiência de leitura, Monteiro Lobato tece por meio da narrativa geograficidades que se vão cristalizando no pensamento do leitor e construindo uma visão de mundo de seu país a partir da formação de uma identidade nacional calcada na exuberância do espaço natural, da exaltação dos recursos naturais disponíveis e de uma visão de futuro que envolve a potencialidade da nação para a construção de uma indústria nacional, representante do progresso econômico e científico pelo qual Lobato acreditava ser a salvaguarda nacional. Ao transpor a responsabilidade da salvaguarda nacional de um elemento humano para um objeto, o espaço geográfico, a geograficidade criada pela narrativa de Lobato facilita a identificação do leitor com o meio, com a ideia de querer pertencer a algum espaço, lugar ou território, pois para onde se mire há a presença constante do herói a ser venerado e preservado: o próprio território brasileiro.

\section{O Le tour de la France par deux enfants} (1877), de G. Bruno

O Le tour de la France par deux enfants pode-se dizer, é um livro de teor geográfico, publicado em 1877 na França por Augustine Fouillée sob o pseudônimo de G. Bruno. Sua trama trata da viagem feita por dois garotos franceses e irmãos, 
André e Julien, de catorze e sete anos, respectivamente, caracterizados por seu criador como diferentes dos outros garotos de sua idade:

[...] André, de catorze anos, é um rapaz robusto, tão grande e forte para sua idade que parece ter ao menos dois anos a mais. Pela mão ele vem segurando seu irmão Julien, um garotinho de sete anos, frágil e delicado como uma menina, apesar de mais corajoso e inteligente que o comum para os garotos de sua idade. (BRUNO, 1877, p. 5).

No contex to de perdas da guerra da Prússia (1870) entre Alemanha e França e com a morte do pai devido a uma doença contraída nos tempos de guerra, os meninos se veem sozinhos no mundo, sem dinheiro e sem rumo, com a certeza de terem apenas um tio vivo, morador do sul do país, na região de Marselha, próxima ao mar Mediterrâneo. Segundo a trama, antes da morte do pai, os meninos habitavam a cidade de Phalsbourg, situada na região da Alsácia-Lorena, no nordeste francês.

Estas informações iniciais e necessárias para situar historicamente o livro de G. Bruno, permitem estabelecer algumas direções importantes na persecução do propósito deste estudo: comparar dois livros de tempos distintos, mas que permanecem unidos a partir de um fio ideológico comum. Ao caracterizar suas personagens como distintas das demais correlatas, corajosas, determinadas, G. Bruno estabelece um diálogo com seu leitor no sentido de fazê-lo identificar-se de imediato com as personagens, afinal, ser grande, corajoso e determinado são traços de personalidade fortemente associados à força e vitória, dois grandes requisitos para os tempos que enfrentava a França, saída derrotada de uma guerra com a vizinha Alemanha.

Não apenas os traços de personalidade dos protagonistas os fazem de imediato "caírem no gosto" do jovem leitor, mas também, a língua nacional aparece como elemento de peso na introdução à trama que se apresenta. Como exemplo do poder da língua e da linguagem como reforçadoras de uma ideologia, no caso a da construção de uma identidade nacional para um povo a ser denominado unicamente de francês, a situação de despedida do pai dos meninos em seu leito de morte, ao fazê-los jurar defender a Alsácia como território francês e que se dedicariam à França o mais que pudessem, revela a importância atribuída ao sentimento patriota à época associado à linguagem como elemento de empoderamento ideológico ao leitor. Prestes a morrer, o pai sussurra: “- 
França!", ao ouvido do filho mais velho, como um eco que ficaria para sempre em sua mente. O diálogo entre as personagens é assim descrito:

O pai lançou um fraco sorriso, mas seu olho, ainda triste, parecia esperar de André outra coisa.

André viu-o preocupado e inquieto e tentou adivinhar [...] Uma palavra mais leve que a respiração veio ao ouvido de André: - França!

- Oh! gritou o filho mais velho de ímpeto, esteja tranquilo, querido pai, eu vos prometo que continuaremos filhos da França; deixaremos Phalsbourg para partir; permaneceremos franceses, ainda que as dificuldades nos façam sofrer por isso. (BRUNO, 1877 , p. 10 - grifo nosso).

A ideia de povo expressada no $L e$ tour de la France par deux enfants aparece como a possibilidade única de um grupo unificado só e somente pelo modus vivendis francês; neste povo e nesta cultura que se organizavam para resistir às perdas territoriais não há espaço para diversidades, sobretudo culturais. E para cristalizar este propósito G. Bruno utilizase da língua como metainstrumento para sua validação, ao exaltar o francês vernáculo a partir dele próprio na escritura de seu livro e lhe inserir uma geograficidade, um sentimento de identificação pelo leitor com o espaço geográfico da Alsácia-Lorena e também do próprio território francês. $\mathrm{O}$ trecho seguinte, referente à passagem dos protagonistas da trama pela região do Delfinado, no sudeste da França, em que o provençal e o occitano eram as línguas maternas, denominadas à época de patoás (patois), expõe esta situação de maneira evidente:

$$
\begin{aligned}
& {[\ldots] \text { O pequeno Julien }[\ldots] \text { veio }} \\
& \text { prostrar-se em pé entre as pernas de } \\
& \text { seu irmão. Ao sentar-se sobre seus } \\
& \text { joelhos e, mirando-o com um ar um } \\
& \text { pouco triste, disse-lhe baixinho: - Por } \\
& \text { que as pessoas desta região não falam } \\
& \text { francês? } \\
& \text { - É por que não puderam ir à escola, } \\
& \text { mas daqui a algum tempo isso não será } \\
& \text { mais assim e por toda a França a }
\end{aligned}
$$
gente saberá falar a língua da pátria. (BRUNO, 1877, p. 164-grifo nosso).

Diana Vidal, ao estudar as práticas de leitura e escrita na escola pública primária do Brasil e da França no final do século XIX, enfatiza uma questão que também aparece com frequência na obra e na linguagem utilizadas por Lobato em seus textos: a oralidade. No entanto, há uma distinção significativa entre a oralidade que Lobato traz e a que a se pode 
verificar no Le tour de la France par deux enfants, sendo naquela narrativa uma oralidade originada na experiência contada e, nesta, em raízes de teor moralizante.

A ideia contida na educação francesa à época era de homogeneização, eliminando qualquer traço religioso, regionalismos culturais e linguísticos, sobretudo. Esta ideia pautou-se pelo reforço da língua falada mais que pela escrita para que, uma vez ouvida, a língua francesa pudesse ser muito bem distinguida por todos e, por sua vez, claramente pronunciada, a ponto de que as pessoas que falassem qualquer outra língua diferente do francês vernáculo fossem automaticamente consideradas como traidoras da pátria. Segundo Vidal:

A imprensa educacional francesa, através de modelos de lições ou de conselhos pedagógicos, preocupava-se em fazer circular os saberes do ler em voz alta, tanto no que concernia ao mecanismo da palavra (boa articulação dos sons) e à expressão do pensamento (dicção), quanto à interpretação gestual e fisionômica.

\section{Homogeneização da linguagem} oral, evitando as diferentes pronúncias e dialetos $[\ldots]$ e ruptura com o modelo religioso de leitura cantada eram também motes dessa nova prática escolarizada. (VIDAL, 2005, p. 80 - grifo nosso).
Assim como Lobato, G. Bruno faz da literatura uma plataforma para lançar suas ideias para com seus leitores e, embora tenham objetivos comuns, os disseminam de maneiras distintas. Se por um lado G. Bruno preocupa-se em formar cidadãos como o próprio nome de seu livro propõe “Dever e pátria” (Devoir et patrie) que deem corpo à ideia de nação por meio das demonstrações constantes de amor à pátria, de sua defesa por meio do trabalho esforçado e da educação para o trabalho, Lobato, por sua vez, caminha no sentido oposto, o da liberdade de pensamento e da tomada de posições pelo jovem leitor. Conforme Martine Watrelot (1999) a narrativa de G. Bruno:

[...] conceberá sob uma roupagem narrativa uma enciclopédia para uso dos estudantes. [...] G. Bruno dará a encontrar em cada uma das etapas que não negligenciam nenhuma região francesa - o itinerário de dois garotos como pretexto à lição de coisas, de moral, de geografia. [...] A celebração das províncias, constante na obra, permite dar ao jovem uma ideia menos abstrata do território nacional $[\ldots .$.$] (WATRELOT, 1999, p.$ 311-312 - grifo nosso).

Para completar a análise inicial a respeito da promoção de uma identidade 
nacional e de uma ideologia nacionalizante entre a juventude francesa leitora de fins do século XIX, a figura dos heróis nacionais vem para reforçar este propósito. Se na Geografia de Dona Benta o herói nacional se faz a partir da figura do espaço geográfico, no Le tour de la France par deux enfants estes virão representados por figuras humanas somente: são filósofos, grandes pensadores, homens de governo e inventores que deram à França sua contribuição. Como aponta José Murilo de Carvalho, os heróis são símbolos poderosos, encarnações de ideias, instrumentos eficazes para atingir a cabeça e o coração dos cidadãos:

[...] Herói que se preze tem de ter, de algum modo, a cara da nação. Tem de responder a alguma necessidade ou aspiração coletiva, refletir algum tipo de personalidade ou de comportamento que corresponda a um modelo coletivamente valorizado. $\mathrm{Na}$ ausência de tal sintonia, o esforço de mitificação de figuras políticas resulta vão. (CARVALHO, 2011, p. 55-56).

A se pensar ainda na situação de busca por referências na construção de um ideário nacionalista, embutida na figura humana dos heróis nacionais cabe a reflexão sobre o papel do trabalho na construção deste ideário que, no pensamento do autor coloca-se ele próprio como o herói da nação, assim como em Lobato, para quem o espaço geográfico assume a função de salvaguarda nacional. Da escrita de G. Bruno é possível experimentar o processo de constituição de um imaginário social do trabalho como salvaguarda nacional a partir da linguagem literária; é ilustrativa desta constatação, dentre outras, o seguinte trecho: "Você quer ganhar a confiança daqueles que você não conhece? Trabalhe. A gente estima sempre aqueles que trabalham." (BRUNO, 1877, p. 37).

\section{Aproximações e distanciamentos: um diálogo entre os livros estudados}

Os grandes temas selecionados para investigação em consonância entre os dois livros estudados compartilham de uma raiz comum, qual seja, a de posicionarem-se no nicho literário da literatura infantil, cujas produções literárias, segundo o pesquisador Ricardo Oriá:

[… procuravam desenvolver nos pequenos leitores o sentimento de amor à Pátria, mediante a exaltação das riquezas naturais $[\ldots]$ e do conhecimento de sua história, através do exemplo edificante dos "filhos ilustres" da terra. 
Ao veicular fatos da $[\ldots]$ história, nos quais emergia quase sempre a figura de heróis nacionais, esse tipo de livro pretendia inculcar nas crianças o patriotismo. (ORIÁ, 2011, p. 42 - adaptado).
Sendo assim a figura 2, na sequência, resume de modo comparativo alguns dos temas discutidos ao longo das narrativas que saltam aos olhos do leitor e que se aproximam ou se distanciam na medida em que são observados à luz do "espírito da época” em que foram pensados:

\begin{tabular}{|c|c|}
\hline \multicolumn{2}{|c|}{ COMPARATIVO ENTRE OS LIVROS ESTUDADOS } \\
\hline \multicolumn{2}{|c|}{ NACIONALISMO E IDENTIDADE NACIONAL } \\
\hline GEOGRAFIA DE DONA BENTA (1935) & LE TOUR DE LA FRANCE PAR DEUX ENFANTS (1877) \\
\hline $\begin{array}{c}\text { - Amor à pátria e ao bem-comum } \\
\text { - Exuberância do espaço natural } \\
\text { - Riqueza do meio natural como fonte de progresso } \\
\text { econômico } \\
\text { - Pautados no cientificismo e no positivismo lógico } \\
\text { - Ideia de povo brasileiro: ressalva à mestiçagem, porém } \\
\text { há predileção do autor pelo modo de vida do homem } \\
\text { branco europeu e americanizado }\end{array}$ & $\begin{array}{c}\text { - Amor à pátria e ao bem-comum } \\
\text { - Exuberância do espaço natural } \\
\text { - Riqueza do meio natural como fonte de progresso } \\
\text { econômico } \\
\text { - Pautados no cientificismo e no positivismo lógico } \\
\text { - Conduz à identificação da pátria com a própria vida do } \\
\text { leitor por meio da vida das personagens } \\
\text { - Ideia de povo: um grupo unificado somente pelo modus } \\
\text { vivendis francês. Não há espaço para diversidade } \\
\text { cultural/racial }\end{array}$ \\
\hline \multicolumn{2}{|c|}{ LITERATURA } \\
\hline GEOGRAFIA DE DONA BENTA (1935) & LE TOUR DE LA FRANCE PAR DEUX ENFANTS (1877) \\
\hline $\begin{array}{c}\text { - Narrativa pautada na desliteraturização do texto: criação } \\
\text { de reconhecimento e apropriação do texto pelo jovem leitor } \\
\text { - Narrador tece aconselhamentos e orienta-se pela } \\
\text { experiência de vida } \\
\text { - Fortemente orientada para a criação de geograficidades } \\
\text { (sentimento de identificação do leitor com o espaço) } \\
\text { - Instrumento de denúncia política e de contato cultural - } \\
\text { viagem cultural }\end{array}$ & $\begin{array}{c}\text { - Narrativa e romance } \\
\text { - Narrador aconselha orientado para a moralidade e não } \\
\text { pela própria experiência } \\
\text { - Fortemente orientada para a criação de geograficidades } \\
\text { (sentimento de identificação do leitor com o espaço) } \\
\text { - Instrumento de denúncia política e de contato cultural - } \\
\text { viagem cultural }\end{array}$ \\
\hline \multicolumn{2}{|c|}{ GEOGRAFIA, CATEGORIAS GEOGRÁFICAS E GEOGRAFICIDADES } \\
\hline GEOGRAFIA DE DONA BENTA (1935) & LE TOUR DE LA FRANCE PAR DEUX ENFANTS (1877) \\
\hline $\begin{array}{c}\text { - Visão de Geografia: ciência que descreve espaços, } \\
\text { porém com a reflexão sobre as ações do homem sobre } \\
\text { eles } \\
\text { - Paisagem: divisão entre natural-rural e urbana } \\
\text { Lugar: associado ao espaço da família } \\
\text { Território: predominância do Estado-nação } \\
\text { - Geograficidades: criação de sentimentos de } \\
\text { pertencimento espacial pela identificação com a nação e } \\
\text { com a pátria - espaços nacionais (indivíduos têm suas } \\
\text { características reforçadas eventualmente como modelo a } \\
\text { ser expandido ou não para o coletivo nacional) }\end{array}$ & $\begin{array}{c}\text { - Visão de Geografia: ciência que descreve espaços. Há } \\
\text { reflexões sobre a atuação do homem neles em toda a } \\
\text { narrativa } \\
\text { - Paisagem: divisão entre natural-rural e urbana } \\
\text { Lugar: associado ao espaço da família } \\
\text { Território: predominância do Estado-nação } \\
\text { - Geograficidades: criação de sentimentos de } \\
\text { pertencimento espacial pela identificação com a nação e } \\
\text { com a pátria - espaços nacionais (características dos } \\
\text { individuos são ausentes) }\end{array}$ \\
\hline
\end{tabular}

Figura 2 - Elaboração: GRACIOLI, 2017 
No comparativo entre os textos o que se denota é uma aproximação das duas narrativas ao ideal positivista de educação, orientado para a razão, para o conhecimento científico e para o progresso das nações, sobretudo. No entanto, o toque de fantasia e de permissão pela imaginação dado por Monteiro Lobato ao seu leitor por meio de sua escrita fabulística vem trazer a este modelo de educação uma ressignificação, que não nega sua raiz ideológica, mas a transfere de modo mais leve e muito mais assimilável do ponto de vista do gosto pela leitura ao seu leitor, como no exemplo da figura 3, na sequência, que revela a mistura entre a fantasia sintetizada pelas personagens e a apresentação de uma localidade como referência ao conteúdo geográfico a ser ensinado.

Um primeiro ponto de convergência entre as narrativas analisadas aproxima-as quanto ao teor de sua origem ideológica. São narrativas que nascem com propósitos semelhantes, porém, tecem-se sob pontos de vista distintos, especialmente quando analisadas à luz da língua e da linguagem que empregam. Na Geografia de Dona Benta, Lobato recupera pela oralidade o sentimento de experiência a ser vivida per si e não por outrem, ao que se pode encontrar algum resquício da atividade cartesiana do pensamento. Como aponta
Jacinto (2015) os estudos literários em comunicação com o conhecimento geográfico associam-se pela ação do viajar, que atribui caráter de itinerância às narrativas: “[ $\ldots .$.$] o cerne e elemento de$ ligação entre Literatura e Geografia é a viagem, que funciona para o escritor como o trabalho de campo para o geógrafo." (JACINTO, 2015, p. 9). Pelo aspecto da viagem, vão se estabelecendo geograficidades que vão atribuindo ao leitor um senso de pertencimento e de posse dos locais que se vão visitando, como um modo de apropriação do bem-comum que é a pátria e que lhe possa despertar um sentimento de cuidado e de dever.

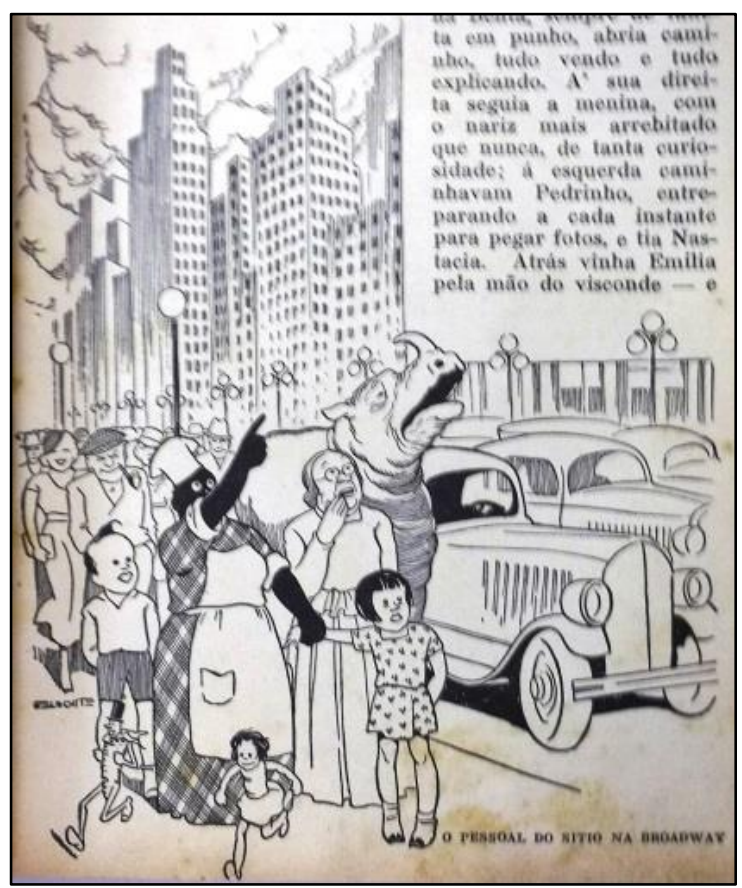

Figura 3 - "O pessoal do sítio na Broadway”. A figura que ilustra a passagem das personagens pelos Estados Unidos não se exime da expressão do pensamento do autor correspondente na palavra escrita: para além de contemplar Nova York, ao leitor, vê-la poderia soar como desejá-la. Embora 
com sua literatura de muitas aberturas para um novo pensamento espacial, Lobato também pode ter contribuído com um movimento de "enrijecer identidades". (LOBATO, 1935, p. 109)

Em ambas as narrativas, ao aproximar a ideia de espaço geográfico ao conceito de nação ou de pátria, os autores atribuem ao objeto geográfico outras conotações; assim, o que era natural passa a ter uma conotação social, ou cultural: um simples vale constituído por fazendas produtoras de gado, com paisagens naturais, deixa de ser um simples vale para ser $o$ vale produtor de leite, $o$ vale mais rico por conta de suas vacas, $o$ vale mais fértil por conta de suas belas e frondosas pastagens e florestas, que devem ser zelados pelo leitor, uma vez que é ele o herdeiro de toda a riqueza que contempla. As figuras 4 e 5 , seguintes, ilustram a grandeza atribuída ao conceito de pátria por meio de ilustrações de grandes obras arquitetônicas ou de lugares naturais de destaque, como cordilheiras, maciços, rios, entre outros elementos agregadores de valor ao espaço da nação.

A semelhança da trama em torno da viagem de personagens crianças protagonistas de aventuras dignas de "gente grande" que se nota em ambas as narrativas é bastante significativa, porém não definitiva, para confirmar a hipótese de que o autor brasileiro tenha contatado o texto francês. Ambas as personagens humanas das narrativas se movem no espaço e no tempo da trama sem a presença efetiva de seus tutores, ainda que auxiliados por outras personagens coadjuvantes; também, estas personagens engajam-se em aventuras de grandes dimensões do ponto de vista da necessidade de responsabilidade, de autonomia e de maturidade, amparadas por dicas e conselhos de sobrevivência e moral, sobretudo.

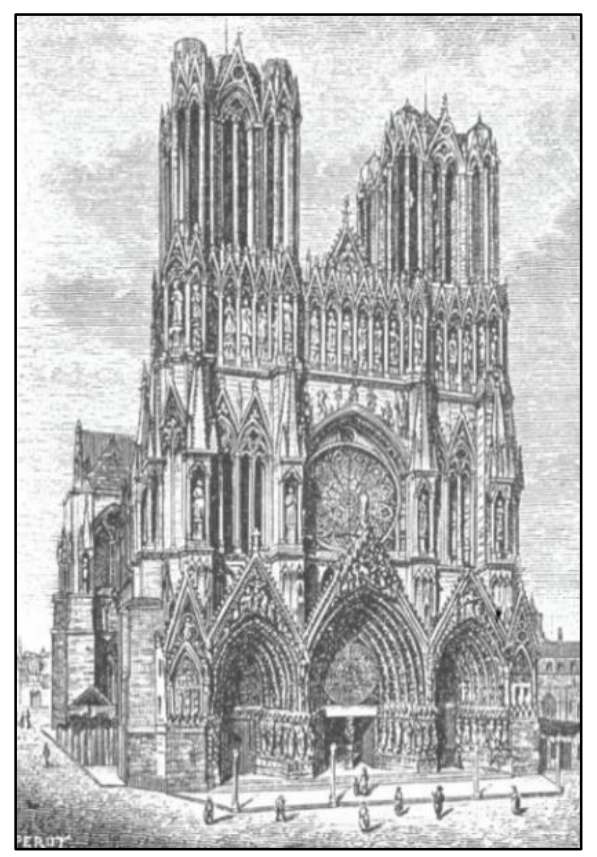

Figura 4 - "La cathédrale de Reims". Fonte: BRUNO, 1877, p. 270

Embora as aproximações entre as tramas das narrativas sejam bastante evidentes, é também verdade que haja distanciamentos entre si. Se no Le tour de la France par deux enfants o conceito de Deus e as ideias de religião, como a da família 
como o centro da vida em comunidade, associada à ideia de pátria, aparecem com frequência na trama, aliados a uma noção de cientificismo na construção do conhecimento, na Geografia de Dona Benta a narrativa prefere a exclusividade do científico como suporte para a divulgação das ideias, tanto isto se comprova pelo fato de que Lobato fora ligado ao movimento escolanovista, que rompia com as noções de Deus e das religiões no ambiente escolar. Também, segundo esta proposta de escola, adotada por Lobato na elaboração de sua narrativa, a ideia estava em dar um poder à criança inexistente até então, fazê-las expressarem seus pensamentos, interligar conhecimentos.

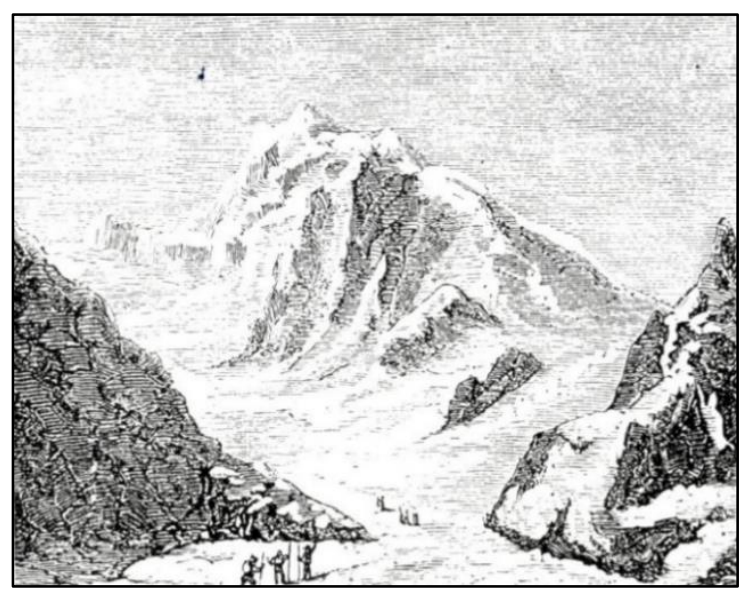

Figura 5 - "Le Mont Blanc". Fonte: BRUNO, 1877, p. 85

\section{Considerações finais}

No texto apresentado, que não se pretende uma análise comparada, a maior aproximação que se pode observar entre as narrativas estudadas resume-se no apontamento da pesquisadora Adriana Silene Vieira (1998) que afirma, para os movimentos das literaturas estudadas, dois caminhos possíveis: “o [da] 'intertextualidade', afirmando que esta ocorre quando um autor utiliza textos de outros, opondo a ela a 'intratextualidade' que é quando o escritor retoma e reescreve sua obra." (VIEIRA, 1998, p. 4 - adaptado).

Em se pautando pelos termos apresentados pela pesquisadora, para as narrativas estudadas conclui-se pelo movimento da intertextualidade, em que Monteiro Lobato visita outras narrativas de seu tempo para compor a sua Geografia, dadas as aproximações entre tramas, papéis desempenhados pelas personagens e objetivos ideológicos; dentre estas narrativas, o Le tour de la France par deux enfants, a pioneira entre todos os tex tos do estilo literatura infantil itinerária do mundo moderno.

Se na Geografia de Dona Benta o propósito linguístico e literário de Monteiro Lobato esteve em romper com a tradição bacharelesca da língua, dura, inacessível pelo leitor em geral, sobretudo pela criança e pelo jovem leitor, nem por isso o seu texto ancora na perspectiva de uma literatura infantil como veículo de moralização ou se propõe a um didatismo 
formalizado na ideia de escola de seu tempo, movimento que, no entanto, se pode perceber no Le tour de la France par deux enfants que, também não sendo utilizado como livro didático, teve um direcionamento eminentemente moralizador e de teor didático à formação intelectual do jovem leitor de seu tempo.

Importa ressaltar que as narrativas estudadas são ambas veiculadoras de geograficidades, cada qual ao seu modo, e é no manuseio artesanal da linguagem, "o logro magnífico que permite sair-se ao poder da língua” (BARTHES, 2010, p. 17) que se diferenciam. São textos cujas tramas colocam-se como substantivadoras do conhecimento geográfico, porque trabalham conceitos e categorias da ciência geográfica de modo leve, nem sempre na obrigação de se os fazer reconhecer como categorias, mas como parte de um conhecimento cujo espaço geográfico é o centro, movimento este de idas e vindas na visitação dos conceitos e categorias geográficas que foi crucial para o desenvolvimento da Geografia como campo de conhecimento científico.

Não apenas uma ciência fundou-se como também um movimento de estilo literário pioneiro no Brasil e no mundo ocidental, o da literatura infantil, pautado em um outro olhar para um sujeito nascente: a criança leitora. Para o caso de
Lobato, embora não se possa considerá-lo criador de uma literatura dirigida ao público infantil, à criança leitora, o próprio escritor reconhece-se pioneiro na empreitada.

O caráter de didatismo a que aspiram as duas narrativas estudadas fornece elementos para a sua consideração como textos de formação e interferência ideológica em várias das gerações de jovens leitores que lhes contataram. O modelo eficiente de transmissão de conhecimentos geográficos, históricos, de bons modos e hábitos por meio da literatura de itinerário faz das duas narrativas verdadeiros pináculos da literatura infantil de seus tempos.

Na literatura de Lobato é bastante perceptível o movimento de recuperação de textos de sua infância, como na sua significativa experiência de leitura de Robinson Crusoé, texto que veicula uma trama de viagem, de movimento pelo espaço geográfico, intertextualidade inspiradora da sua Geografia e do Le tour de la France par deux enfants. Vieira (1998) confirma esta colocação ao apontar que: “aparentemente, o projeto lobatiano de uma literatura infantil tem suas raízes na experiência de Lobato enquanto leitor, recuperando suas leituras de menino e de rapaz" (VIEIRA, 1998, p. 28) reforçando a hipótese inicialmente proposta para este 
estudo. De modo que a investigação que se apresenta não se faz esgotada, conclui-se que o texto apresentado aponta para uma substantivação do conhecimento geográfico aliado aos campos da literatura e da educação.

\section{NOTAS}

* Artigo publicado parcialmente na Revista Brasileira de Educação em Geografia (EDUGEO ISSN: 2236-3904) na seção Artigos inéditos, referente ao v. 7, n. 13, jan./jul. 2017 sob o título "Imbricações geográficas, literárias e educacionais entre a Geografia de Dona Benta (1935) e o Le tour de la France par deux enfants (1877)”. O artigo não se encontra em exame para publicação por nenhum outro periódico ou editor.

* Universidade Estadual Paulista Júlio de Mesquita Filho - UNESP Rio Claro/Instituto de Biociências/Depto. Educação. Fundação de Amparo à Pesquisa do Estado de São Paulo-FAPESP. Geógrafo. Mestre em Educação. Doutorando em Educação. Pesquisador e professor-tradutor francês-português no município de Rio Claro-SP. Trabalha com a temática Geografia, literatura e educação. filipe-rg@hotmail.com.

*** Universidade Estadual Paulista Júlio de Mesquita Filho - UNESP Rio Claro / Instituto de Biociências/Depto. Educação. Geógrafo. Mestre em Educação. Doutor em Educação. Trabalha com a temática da formação de professores em Geografia. jpezzato@,rc.unesp.br

Apoio Financeiro: FAPESP - Fundação de Amparo à Pesquisa do Estado de São Paulo. Processo $n^{\circ}$. 2014/21402-2.

\section{REFERÊNCIAS BIBLIOGRÁFICAS}

BAKHTIN, Mikhail. Metodologia das ciências humanas. In:__ Estética da criação verbal. 4 ed. São Paulo: Martins Fontes, 2003, p. 393-410.

BARTHES, Roland. Aula. 11 ed. São Paulo: Cultrix, 2010.

BRUNO, G. Le tour de la France par deux enfants. Devoir et patrie. Paris: Librairie Classique d'Eugene Belin, 1877, 330p.

CARVAlHO, José Murilo de. A formação das almas - o imaginário da república no Brasil. São Paulo: Companhia das Letras, 2011.

DARDEL, Eric. O Homem e a Terra. Natureza da realidade geográfica. São Paulo: Perspectiva, 2011 , $159 \mathrm{p}$.

GERALDI, João Wanderley. Culturas orais em sociedades letradas. Educação \& Sociedade. n. 73, [s.n.], [s.l.], dez. 2000, p. 100-108.

GINZBURG, Carlo. Sinais: raízes de um paradigma indiciário. In: Mitos, emblemas, sinais morfologia e história. São Paulo: Companhia das Letras, 1999, p. 143-179.

GRACIOLI, Filipe Rafael. A identidade nacional e a formação do espaço-nação na experiência literária da Geografia de Dona Benta, de Monteiro Lobato. 2013. 129f. Dissertação de mestrado em Educação. UNESP - Universidade Estadual Paulista "Júlio de Mesquita Filho". Rio Claro. 2013.

JACINTO, Rui. (D)escrever a Terra: geografia, literatura, viagem. A geografia de Portugal segundo José Saramago. GEOgraphia. n. 33, [s.n.], [s.l.], 2015, p. 9-40.

LOBATO, Monteiro. Geografia de Dona Benta. 22 ed. São Paulo: Brasiliense, 1988, 136p.

ORIÁ, Ricardo. O Brasil contado às crianças. Viriato Corrêa e a literatura escolar brasileira (1934-1961). São Paulo: Annablume, 201 1, 274p.

VIDAL, Diana Gonçalves. Culturas escolares. Estudo sobre as práticas de leitura e escrita na escola pública primária (Brasil e França, final do século XIX). Campinas: Autores Associados, 2005.

VIEIRA, Adriana Silene. "Um inglês no sítio de Dona Benta”. Estudo da apropriação de Peter Pan na obra infantil lobatiana. 1998. 170f. Dissertação de mestrado. UNICAMP. Programa de Pós-graduação em Teoria Literária. Campinas. 1998 
WATRELOT, Martine. Aux sources du "Tour de la France par deux enfants". Revue d'Histoire moderne et contemporaine. n. 46-2. [s.n.], [s.l.]. avril/juin. 1999, p. 311-329.

\section{GEOGRAPHICAL, LITERARY AND EDUCATIONAL IMPLICATIONS: BETWEEN GEOGRAFIA DE DONA BENTA (1935) AND LE TOUR DE LA FRANCE PAR DEUX ENFANTS (I877)}

ABSTRACT: THE TEXT ESTABLISHES SIMILARITIES BETWEEN CHILDREN'S LITERATURE AND GEOGRAPHY FROM THE ANALYSIS OF GEOGRAPHICAL CHARACTER OF NARRATIVES ORIENTED READER CHILD THE PERIOD FROM THE LATE XIXTH CENTURY AND EARLY XXTH CENTURY: THE GEOGRAFIA DE DONA BENTA (1935) AND LE TOUR DE LA FRANCE PAR DEUX ENFANTS (1877). THE AIM OF THIS STUDY LIES IN THE DISCUSSION OF THE SIMILARITIES AND DIFFERENCES BETWEEN THE NARRATIVES IN SOME ASPECTS, SUCH AS THE CREATION OF NATIONAL IDENTITIES, JUXTAPOSE OTHER RELATED TOPICS. AS METHOdOLOGICAL FRAMEWORK PRESENTS the EVIDENTIARY PARADIGM, WHICH POINTS TO THE IDEA tHAT thERE IS EVIDENCE IN THE TEXT THAT REVEAL NEGLIGIBLE PECULIARITIES, AS RELEVANT KNOWLEDGE IN UNDERSTANDING THE WORLDVIEW OF THE AUTHORS. THE HYPOTHESIS PURSUED LIES IN THE IDEA THAT LOBATO HAS BEEN INSPIRED BY FRENCH BOOK FOR THE DEVELOPMENT OF HIS TEXT, GIVEN THE PLOT SIMILARITIES BETWEEN THE TEXTS, IN ADDITION TO THE SIMILARITIES BETWEEN THE REFERENCE CONTENT TO THE FIELDS OF EDUCATION AND GEOGRAPHY. THE STUDY RETRIEVES A tYPE OF WRITING tHAT OPENS FOR CHILDREN A "JOURNEY LITERATURE”, COMBINING LITERATURE AND GEOGRAPHY SO EVER SEEN IN WRITING DIRECTED TO THE CHILD.

KEYWORDS: CHILDREN'S LITERATURY, GEOGRAPHY, EDUCATION. 


\section{NARRATIVES EN DIALOGUE: IMPLICATIONS GÉOGRAPHIQUES, LITTÉRAIRES ET ÉDUCATIVES}

\section{ENTRE LA GEOGRAFIA DE DONA BENTA (1935) Et LE TOUR DE LA FRANCE PAR DEUX ENFANTS (1877)}

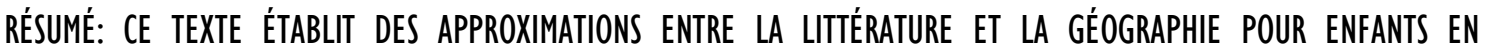
FONCTION DE L'ANALYSE dES DEUX RÉCITS GÉOGRAPHIQUES ORIENTÉS VERS LES ENFANTS LECTEURS DE LA PÉRIIDE COMPRISE ENTRE LA FIN DU XIXE SIĖCLE et LE DÉBUt DU XXE SIĖCLE: La GEOGRAFIA DE DONA BENTA (1935) DE

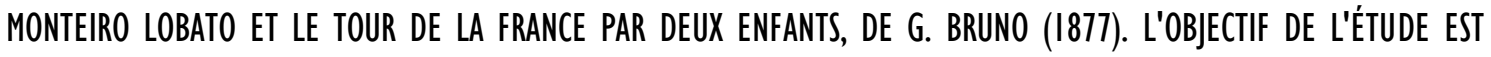
DE DISCUTER deS APPROXIMATIONS Et deS DISTANCES ENTRE LES RÉCITS DANS CERTAINS ASPECTS, COMME LA CRÉATION

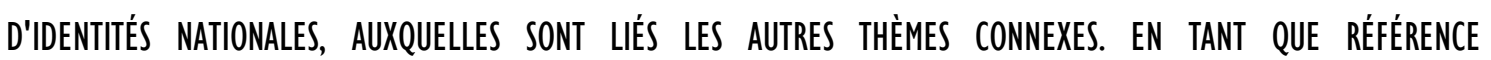
MÉTHODOLOGIQUE, IL Y A LE PARADIGME INDIIIAIRE, QUI SOULIGNE L'IDÉE QU'IL EXISTE DES INDICES DANS LE TEXTE QUI RÉvètLENT dES PARTICULARITÉs NÉGLIGEABLES, EN TANT QUE CONNAISSANCES PERTINENTES DANS LA COMPRÉHENSION DE LA VISION DU MONDE DES AUTEURS. L'HYPOTHĖSE POURSUIVIE RÉSIDE DANS L'IDÉE QUE LOBATO S'INSPIRE DU LIVRE FRANÇAIS POUR LE dÉVELOPPEMENT DE SON RÉCIT, COMPTE TENU DES SIMILITUDES ENTRE LES teXTES ET LES

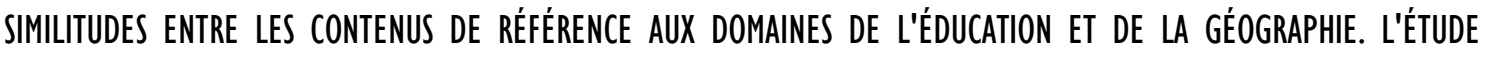

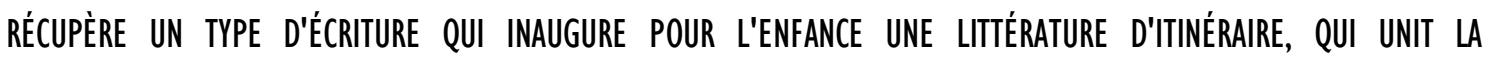
LITTÉRATURE Et la GÉOGRAPHIE d'UNE MANière JaMAIS VUE dans l'ÉCRITURE ORIENTÉE SUR L'ENFANCE EN OCCIDENT. MOTS-CLÉS: LITTÉRATURE POUR ENFANTS, GÉOGRAPHIE, ÉDUCATION. 